\title{
Designing a Large Scale Cooperative Sync\&Share Cloud Storage Plattform for the Academic Community in Northrhine-Westfalia
}

\author{
Raimund Vogl ${ }^{1}$, Holger Angenent ${ }^{2}$, Rainer Bockholt ${ }^{3}$, Dominik Rudolph ${ }^{4}$, Stefan Stieglitz ${ }^{5}$, Christian \\ Meske $^{6}$ \\ 1,2,4 Westfälische Wilhelms-Universität Münster, Röntgenstraße 7-13, 48149 Münster/Germany, \\ \{rvogl|h.angenent|d.rudolph\}@uni-muenster.de \\ ${ }^{3}$ Rheinische Friedrich-Wilhelms-Universität Bonn, Wegelerstraße 3, 53115 Bonn, \\ rainer.bockholt@uni-bonn.de \\ ${ }^{5,6}$ Westfälische Wilhelms-Universität Münster, Leonardo Campus 11, 48149 Münster/Germany, \\ \{stefan.stieglitz|christian.meske\}@uni-muenster.de
}

Keywords

cloud services, cloud storage, collaboration, cooperative project.

\section{ABSTRACT}

Cloud storage services allowing to synchronize file folders on multiple devices and to exchange data between users for collaboration are gaining substantial public recognition lately, due to the proliferation of mobile and personal devices like smartphones and tablets. Utilization of such services, either free or paid, like Dropbox, GoogleDrive, or Microsoft SkyDrive, in the academic community is not uncommon, even for storing sensible data from research and teaching. This creates substantial data privacy and confidentiality issues, even putting the individual user at legal risk (cf. Catteddu et al. 2009; Hoboken et al. 2012). Guidelines for usage considerations for public cloud services, as have been imposed by several universities in Germany, try to create awareness among scholars, and in some cases, data security officers even officially ban the use of public cloud storage services.

With most of the IT departments at universities not being able to readily provide on premise alternatives compliant with data security policies, such bans certainly are not likely to succeed.

A representative survey amongst academic users on cloud storage services conducted at the University of Münster in 2012 (cf. Zentrum für Informationsverarbeitung 2012) and 2013 (cf. Lucal J.A., 2013) show very strong demand amongst both researchers and students for an on premise service alternative provided by university IT, and high awareness for data security issues connected with public cloud services hosted in non-EU countries.

It turned out that $96 \%$ of the participants already use cloud services such as Dropbox, Google Drive or iCloud. However, only half of the students store private data while almost $90 \%$ synchronize, share and backup study-related files. According to the participants, sharing of folders with other students, high usability, and a local desktop client are the most required functionalities. Furthermore, students stated that they would prefer to use a service which is provided by a reliable public institution (e.g. university) which is subject to the German law on data protection.

With this background, the community of the IT managers for the 14 research universities in Germany's most populous state of Northrhine-Westfalia (NRW) has brought underway a project to set up a cooperatively operated cloud storage platform for researchers and students - Sync\&Share NRW. A consortium of research and applied sciences universities headed by the University of Münster covering approx. $60 \%$ the academic community in NRW has been formed and a funding proposal is to be filed shortly. A system for possibly up to 500,000 users is being designed by a joined task force of IT staff members from several universities drawing on input from companies with suitable product offerings either in closed or open source.

To ensure adequate storage quotas for both individual use and for project group collaboration, storage space of 6 Petabyte is envisioned to be needed. To keep resource consumption for data center real estate and network bandwidth at an acceptable level, a distributed deployment of the 
storage system at 3 major universities is considered, underlining the cooperative character of this endeavor. Since end user administration and support has to be kept at a minimum in a service of this scope, self-enrollment with user authentication and authorization based on a federated identity management founded on the Shibboleth authentication and authorization infrastructure provided by the German Research Network (DFN-AAI), is considered. Current activities by DFN to create legal templates for cooperative cloud services within the German academic community provide collateral support for the organizational framework of the Sync\&Share NRW consortium. Accompanying user acceptance and service adaption studies conducted by the Communication and Collaboration Systems working group at Münster University's European Research Center for Information Systems based on well-proven theoretical approaches like the Technology Acceptance Model (TAM) (cf. Bagozzi 2007; Brown et al. 2002; Legris et al. 2003) or the Theory of Planned Behavior (TPB) (cf. Ajzen 1991) and recent work on cloud computing in an academic environment (e.g. Ajith et al. 2012; Behrend et al. 2011; Katz et al.2009; Khmelevsky et al. 2010; Sultan 2010) are to provide valuable input for the crucial sync\&share software features (possibly even additional cooperation tools on top of the baseline Sync\&Share service) and the optimum timeline for a phased hardware delivery, to avoid resource bottlenecks and ensure user satisfaction when Sync\&Share NRW is to go live in the targeted timeframe of early 2014.

\section{REFERENCES}

Ajith S. N., Hemalatha, M. (2012). Cloud Computing for Academic Environment. In: International Journal of Information and Communication Technology Research, 2, 97-101.

Ajzen, I. (1991). The Theory of Planned Behavior. In: Organizational Behavior and Human Decision Processes, 50, 179-211. http://dx.doi.org/10.1016/0749-5978(91)90020-T

Bagozzi, R. P. (2007). The Legacy of the Technology Acceptance Model and a Proposal for a Paradigm Shift. In: Journal of the Association for Information Systems, 8. http://aisel.aisnet.org/jais/vol8/iss4/12

Behrend, T. S., Wiebe, E. N., London, J. E. \& Johnson, E. C. (2011). Cloud Computing Adoption and Usage in Community Colleges. In: Behavior and Information Technology, 30, 231-240. http://dx.doi.org/10.1080/0144929X.2010.489118

Brown, S. A., Massey, A. P., Montoya-Weiss, M. M. \& Burkman, J. R. (2002). Do I really have to? User Acceptance of Mandated Technology. In: European Journal of Information Systems, 11 (4), 283-295. http://dx.doi.org/10.1057/palgrave.ejis.3000438

Catteddu, D., Hogben, G. (2009). Cloud Computing. Benefits, Risks and Recommendations for Information Security. In: The European Network and Information Security Agency (ENISA).

Hoboken, J. V., Arnbak, A. \& Eijk, N. V. (2012). Cloud Computing in Higher Education and Research Institutions and the USA Patriot Act. In: SSRN eLibrary.

Katz, R. N., Goldstein, P. J. \& Yanosky, R. (2009). Demystifying Cloud Computing for Higher Education. In: EDUCAUSE Center for Applied Research, 19, 1-13.

Khmelevsky, Y., Voytenko, V. (2010). Cloud Computing Infrastructure Prototype for University Education and Research. In: Proceedings of the 15th Western Canadian Conference on Computing Education (WCCCE) 2010, http://doi.acm.org/10.1145/1806512.1806524 2010.

Legris, P., Ingham, J. \& Collerette, P. (2003). Why do People use Information Technology? A critical Review of the Technology Acceptance Model. In: Information and Management, 40 (3), 191-204. http://dx.doi.org/10.1016/S0378-7206(01)00143-4

Lucas, J.A. (2013): Die Einführung einer Cloud Storage-Lösung an der Westfälischen WilhelmsUniversität Münster. Eine empirische Analyse für erfolgreiches Change Management. BachelorThesis. Münster: unpublished.

Mircea, M., Andreescu, A. (2011). Using Cloud Computing in Higher Education: A Strategy to Improve Agility in the Current Financial Crisis. In: Communications of the IBIMA, 1-15. http://dx.doi.org/10.5171/2011.875547

Sultan, N. (2010): Cloud Computing for Education: A new Dawn? In: International Journal of Information Management, 30 (2), 109-116.

Zentrum für Informationsverarbeitung (2012): ZIV-Nutzerbefragung 2012. Ergebnisse. 
http://www.unimuenster.de/imperia/md/content/ziv/pdf/nutzerbefragung_2012_kurz.pdf

\section{AUTHORS' BIOGRAPHIES}

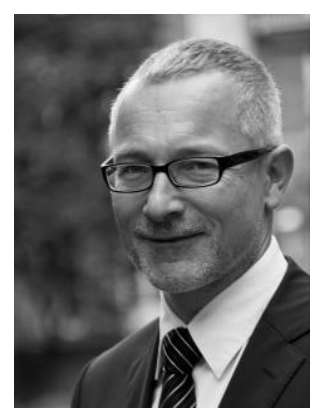

R. Vogl holds a Ph.D. in elementary particle physics from the University of Innsbruck (Austria). After completing his Ph.D. studies in 1995, he joined Innsbruck University Hospital as IT manager for medical image data solutions and moved on to be deputy head of IT. He served as a lecturer in medical informatics at UMIT (Hall) and as managing director for a medical image data management software company (icoserve, Innsbruck) and for a center of excellence in medical informatics (HITT, Innsbruck). From 2007 on, he is Director of ZIV (Zentrum für Informationsverarbeitung - the university computing center) for the University of Münster (Germany).

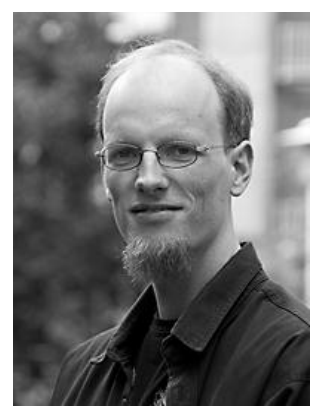

H. Angenent is a Research Assistant at the Zentrum für Informationsverarbeitung (the university computing center) at the University of Münster in Germany and responsible for high performance computing systems and cloud services. He studied theoretical physics at University of Münster and is currently finalizing his Ph.D. thesis.

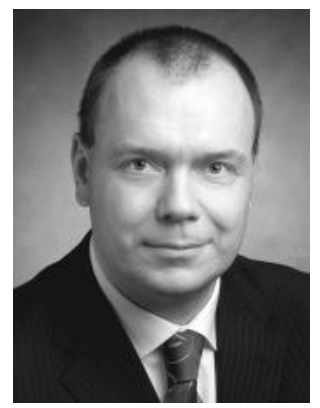

R. Bockholt holds a Ph.D. in microbiological sciences from the University of Bielefeld (Germany). After finishing Ph.D. studies in 1995, he joined IT.NRW as head of the IT service center. From 1999 on, he was a Research Assistant at the computing center of Bielefeld University, and moved on to be Director of the computing center of the University of Bonn in 2003. He is presently the spokesperson for ARNW (working group of IT directors of Universities in NRW), a chairman of the ZKI working group for network services and a member of the operating committee for DFN (German research network).

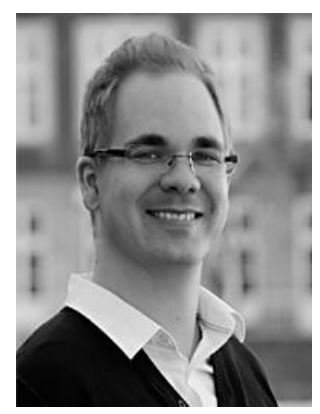

D. Rudolph is a Research Assistant and from 2011 on a member of the management at the Zentrum für Informationsverarbeitung (the university computing center) at the University of Münster in Germany, where he is responsible for human resources, organization and marketing. He studied communication sciences, economics and modern history at the University of Münster and is a Ph.D. candidate. His research focuses on the diffusion of media innovations from the user perspective.

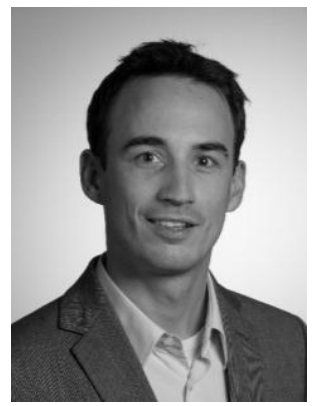

S. Stieglitz is an Assistant Professor in communication and collaboration management at the Department of Information Systems at the University of Münster in Germany. He studied business economics and received his doctorate degree at University of Potsdam in Germany. He is the founder and academic director of the Competence Center Connected Organization at the European Research Center for Information Systems (ERCIS). Of particular interest in his work is to investigate the usage of social media in enterprises and political context. He published several articles in reputable international journals such as Journal of Management Information Systems, Communications of the AIS, 
Social Network Analysis and Mining, and MIS Quarterly Executive.

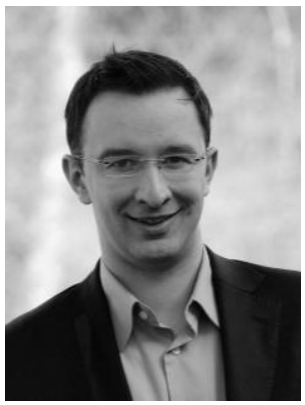

C. Meske is a Research Assistant and Ph.D. candidate at the Research Group for Communication and Collaboration Management at the Department of Information Systems at the University of Münster in Germany. He was a Visiting Scholar in the Discipline of Business Information Systems at the University of Sydney Business School and is a member of the Competence Center Connected Organization at the European Research Center for Information Systems (ERCIS). He studied Business Administration at the University of Potsdam in Germany. His research focuses on the governance, management, and adoption of innovative technologies within organizations. 